\title{
Management of wireworm damage in maize fields using new, landscape-scale strategies
}

\author{
Stéphanie Saussure • Manuel Plantegenest • \\ Jean-Baptiste Thibord • Philippe Larroudé • \\ Sylvain Poggi
}

Accepted: 28 November 2014 / Published online: 14 January 2015

(C) INRA and Springer-Verlag France 2015

\begin{abstract}
Crop-damaging wireworms - the soil-dwelling larvae of click beetles - have resurged in Europe over the past 15 years, particularly in French maize crops. There is currently no curative treatment available to control wireworms, and preventive treatments are mainly chemical. We therefore need to better understand factors that rule damage for developing agroecological control strategies. In this investigation, we tested the effect of agricultural practices and local landscape on wireworm damage in maize crops. We surveyed wireworm damage in 341 fields under various conditions in western France in 2011 and 2012. We used in particular a random forest algorithm to impute missing values and an automated model selection routine to select the best beta regression model. Our results show that the occurrence of grassland in the rotation increases wireworm damage. Tillage also shows a high influence, though varying with season and year. Wireworm damage is decreased by the presence of hedges or cultivated crops at the field border, whereas it is increased by the presence of grassland at the field border. Overall, our findings provide some insights to develop preventive solutions for the sustainable control of wireworms, as well as a framework for data processing to analyze a wide range of similar situations involving other crops and pests.
\end{abstract}

S. Saussure $\cdot$ M. Plantegenest

Agrocampus Ouest, UMR 1349 IGEPP, 65 rue de Saint Brieuc, CS84215, 35042 Rennes, France

S. Saussure $\cdot$ S. Poggi $(\bowtie)$

INRA, UMR 1349 IGEPP, Domaine de la Motte, BP 35327,

35653 Le Rheu Cedex, France

e-mail: sylvain.poggi@rennes.inra.fr

S. Saussure $\cdot$ J.-B. Thibord $\cdot$ P. Larroudé

Arvalis Institut du Végétal, Agrosite 21, Chemin de Pau,

64121 Montardon, France
Keywords Wireworm damage $\cdot$ Crop protection · Agricultural practices $\cdot$ Landscape context $\cdot$ Model selection · Beta regression

\section{Introduction}

Potential yield losses caused by pests, diseases, and weeds on the world's main crops have been assessed at about $70 \%$ (Oerke and Dehne 2004), requiring the use of efficient crop protection methods. In some cases, no curative solution is available to treat crops when damage becomes apparent. Wireworms, the soil-dwelling larvae of click beetles (Coleoptera: Elateridae), are one such example (e.g., Furlan 2005; Barsics et al. 2013). Farmers therefore adopt preventive crop protection strategies that are generally based on the use of chemicals. However, an increasing number of studies have demonstrated the negative effects of chemicals on human health, on biodiversity, and even on agricultural sustainability because they decimate natural pest enemies or promote pest and disease resistance (Geiger et al. 2010; Wilson and Tisdell 2001). Thus, there is a rapidly increasing demand for new environmentally friendly crop protection strategies. The identification of the determining factors that lead to crop damage is one approach that can optimize the use of preventive solutions.

Wireworms are important polyphagous pests and have been reported since the beginning of the twentieth century in Europe (Miles and Petherbridge 1927; Traugott et al. 2008). Over the past 15 years, they have resurged (Parker and Howard 2001). Controlling wireworms has recently become a prime issue because a European moratorium has banned in 2014 the main insecticide used against this pest: the thiamethoxam. Maize is sensitive to wireworms from germination until the eight-leaf phenological stage (Taupin 2007), or even later (the twelve-leaf stage) in some situations. Larvae 
attack seeds, young roots, and the base of stems. They can cause a reduction in seedling density or even death of young plants (Chaton et al. 2003). When plants survive, the attack may impede seed production, induce abnormal tillering, or in the less serious cases, produce bleached stripes on central leaves (Fig. 1). In France, attacks on $10 \%$ of maize plants in a field correspond to a loss of 500 to $1000 \mathrm{~kg} / \mathrm{ha}$ (Larroudé, unpublished data).

The frequency and intensity of wireworm damage in France vary across regions. Fields exhibiting high larval populations tend to be spatially clustered (Erichsen 1944). The distribution of adult click beetles in the landscape is patchy and can be stable for several consecutive years (Blackshaw and Hicks 2013; Blackshaw and Vernon 2006). At a smaller scale, Salt and Hollick (1946) confirmed farmers' observation that damage can appear in the same area of the field over several years. Taken together, these features suggest that regional and field characteristics including agricultural practices and the landscape context are important factors in determining the wireworm population (see Parker and Seeney 1997).

Due to the multiannual biological cycle of wireworms (Furlan 2004; Parker and Howard 2001), crop rotation is considered a good agricultural practice for controlling damage when it includes nonhost plant species. Wireworms preferentially live in grasslands that provide favorable conditions for eggs and larvae in terms of moisture, soil temperature, and nutrient resources (Furlan 2004; Miles 1942; Parker and Howard 2001). However, when no suitable plant species are present, wireworms can still survive starvation by feeding on organic matter (Gough and Evans 1942).

Larvae migrate vertically through soil according to soil microclimate and depending on the interaction between climate and soil texture. In Europe, they generally migrate twice a year, in spring and in autumn, when abiotic conditions are favorable in the upper soil layers (Jung et al. 2012; Miles 1942), making them vulnerable to tillage at this period. Tillage reduces populations of eggs and young larvae by damaging them mechanically. It brings them to the soil surface, where they are exposed to predation. At the soil surface, the youngest stages can also suffer from desiccation (Lees 1943). Delaying the sowing date may therefore help reduce damage by desynchronizing the period of wireworm presence in the upper soil layers and the period during which maize is sensitive to wireworm attacks and by favoring late tillage operations, which are more detrimental to larvae.

To our knowledge, no studies have attempted to quantify the simultaneous influence of agricultural and landscape characteristics on the level of damage caused by wireworms in maize.

The main purpose of our study was to assess the influence of the local landscape features and agricultural practices on the level of wireworm damage characterized by the proportion of the damaged area in a field. To diagnose fields at risk for

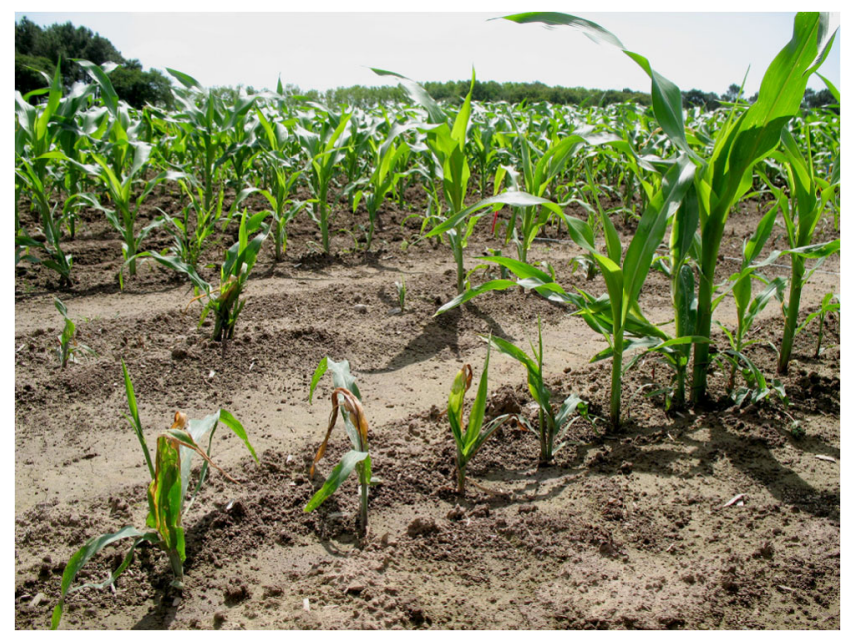

Fig. 1 Damage caused by wireworms in a maize field. Possible symptoms include a reduction in seedling density, mortality of young plants, reduction in plant growth, abnormal tillering, and presence of a bleached stripe on central leaves

wireworm damage, we used putative explanatory variables that could be easily assessed by farmers or agricultural agents, such as crop rotation or tillage operations (see Table 1 for a complete list). A dataset covering a large geographical area from northwestern to southwestern France was compiled. In this type of survey, high correlations between variables and a high proportion of missing values are common. To overcome this difficulty, we developed a framework for data processing that can be applied to other similar datasets. We employed a scheme of variable selection and missing data treatment using a random forest algorithm to produce a revised dataset well suited to beta regression. Unlike linear regression models, beta regression models are tailored to situations in which the response variable is a proportion (i.e., a continuous measure over the standard unit interval). Implementing an automated model selection method based on Akaike information criteria (AIC) and model averaging, we identified the most influential explanatory variables and compared our best model predictions to field observations of crop wireworm damage. Our results may provide insight for the development of a management strategy to prevent wireworm damage in maize crops in western France.

\section{Materials and methods}

\subsection{The agroenvironmental survey}

A vast survey was conducted over two consecutive years. It concerned a total of 119 fields in 2011 and 222 fields in 2012 spreading from northwestern to southwestern France (Fig. 2a). Many variables were collected to describe the agricultural practices applied before and during the cropping season, the soil properties, and the local landscape features (i.e., the 
Table 1 List and description of the explanatory variables included in the full model

\begin{tabular}{|c|c|c|c|}
\hline Variable & Full name & Description & Selected \\
\hline \multicolumn{4}{|c|}{ Agricultural practices } \\
\hline $\mathrm{GrPa}$ & Grass ley history & $\begin{array}{l}\text { Presence/absence of a grass ley in the crop rotation } \\
\text { sequence in the last } 20 \text { years }\end{array}$ & Yes $(1.5 \%)$ \\
\hline TyRo & Rotation sequence & $\begin{array}{l}\text { Rotation sequence in the last } 5 \text { year: short (max. } 2 \text { crop)/long } \\
\text { (more than } 3 \text { crop)/maize monoculture/including a grass ley }\end{array}$ & Yes $(1.5 \%)$ \\
\hline $\mathrm{T} 4 \mathrm{Sp}$ & Past spring tillage & $\begin{array}{l}\text { Number of tillage operations between March and June in } \\
\text { the last } 4 \text { years }\end{array}$ & No $(55.1 \%)$ \\
\hline $\mathrm{T} 4 \mathrm{Su}$ & $\begin{array}{l}\text { Past summer } \\
\text { tillage }\end{array}$ & $\begin{array}{l}\text { Number of tillage operations between July and October in } \\
\text { the last } 4 \text { years }\end{array}$ & No $(41.4 \%)$ \\
\hline T4Wi & Past winter tillage & $\begin{array}{l}\text { Number of tillage operations between November and } \\
\text { February in the last } 4 \text { years }\end{array}$ & No $(53.7 \%)$ \\
\hline TiSp & Spring tillage & Number of tillage operations between March and sowing & Yes (10.3) \\
\hline TiWi & Winter tillage & $\begin{array}{l}\text { Number of tillage operations between November and } \\
\text { February before sowing }\end{array}$ & Yes $(11.1 \%)$ \\
\hline SoDa & Sowing date & Sowing date (in Julian days) & Yes $(0 \%)$ \\
\hline \multicolumn{4}{|c|}{ Soil properties } \\
\hline SoTe & Soil texture & $\begin{array}{l}\text { Soil texture estimated by farmer according to a texture } \\
\text { triangle }\end{array}$ & Yes $(1.2 \%)$ \\
\hline OrMa & $\begin{array}{l}\text { Assessment of } \\
\text { organic matter }\end{array}$ & Organic matter content in percentage & Yes $(35.2 \%)$ \\
\hline PrOr & $\begin{array}{l}\text { Precision of } \\
\text { organic matter }\end{array}$ & $\begin{array}{l}\text { Method of quantification of the organic matter content: } \\
\text { farmer expertise/soil chemical analysis }\end{array}$ & Yes $(35.2 \%)$ \\
\hline \multicolumn{4}{|c|}{ Landscape context } \\
\hline Gras & Grassland & Presence/absence of grassland at the perimeter of the field & Yes $(0 \%)$ \\
\hline Crop & Crop & $\begin{array}{l}\text { Presence/absence of another cultivated crop at the perimeter } \\
\text { of the field }\end{array}$ & Yes $(0 \%)$ \\
\hline Hedg & Hedge & Presence/absence of hedge at the perimeter of the field & Yes $(0 \%)$ \\
\hline \multicolumn{4}{|c|}{ Forced variables } \\
\hline DuSO & $\begin{array}{l}\text { Duration of } \\
\text { potential attack }\end{array}$ & $\begin{array}{l}\text { Number of days between the sowing and the date of damage } \\
\text { assessment }\end{array}$ & Yes $(0 \%)$ \\
\hline TyIn & $\begin{array}{l}\text { Type of } \\
\text { insecticide }\end{array}$ & Type of insecticide used: thiamethoxam/pyrethroid/none & Yes $(0.3 \%)$ \\
\hline Year & Year & Year of survey & Yes $(0 \%)$ \\
\hline Segm & Segment & $\begin{array}{l}\text { Homogeneous geographical unit based on a classification by } \\
\text { Arvalis Institut du Végétal }\end{array}$ & Yes $(1.2 \%)$ \\
\hline
\end{tabular}

The last column indicates whether the variable was included in the final (best) model according to the employed selection procedure. The proportion of missing data is shown in parentheses

presence or absence of targeted landscape elements such as hedges, crops, and grassland at the perimeter of the surveyed field). The past agricultural practices were characterized by the number of tillage operations and their period of application, the presence or absence of a grass ley during the last 20 years in the crop rotation, and the crop rotation sequence used by the farmer during the last 4 years. The agricultural practices applied during the study cropping season were the sowing date, the type of insecticide applied (if any), and the period and number of tillage operations before sowing. Soil properties included the amount of organic matter and soil texture. When laboratory analyses were not available, soil properties were directly assessed by farmers on the basis of their knowledge of their fields and of the regional context. In some cases, laboratory analyses and expert assessment were both available and were compared. They showed sufficient consistency to allow farmers' appraisals being used (though less accurate). Yet, to account for a possible bias in farmers' estimates, a categorical variable was introduced in the models to indicate which type of assessment was used. To account for the large variation in climate and agricultural practices over the investigated territory, fields were clustered into homogeneous geographical units called "segments," based on the classification proposed by Arvalis Institut du Végétal. A segment is a homogenous geographical unit based on expert knowledge on local soil type, local climate, and the dominant farming system. Finally, crop damage was estimated for each field. The most problematic click beetle species in maize in France belong to the genera Agriotes, which lay their eggs in clumps in the spring for several months (Furlan 2004; Parker and Howard 2001). Larval populations can be either strongly aggregated or randomly distributed (Cherry and Stansly 2008; Salt and Hollick 1946), possibly in relation to their age (Doane 
Fig. 2 Field surveys in western France. a The townships in which one or more surveyed fields were located are indicated by open triangles for 2011 data and filled circles for 2012 data. b Levels of wireworm damage observed in 2011 and 2012

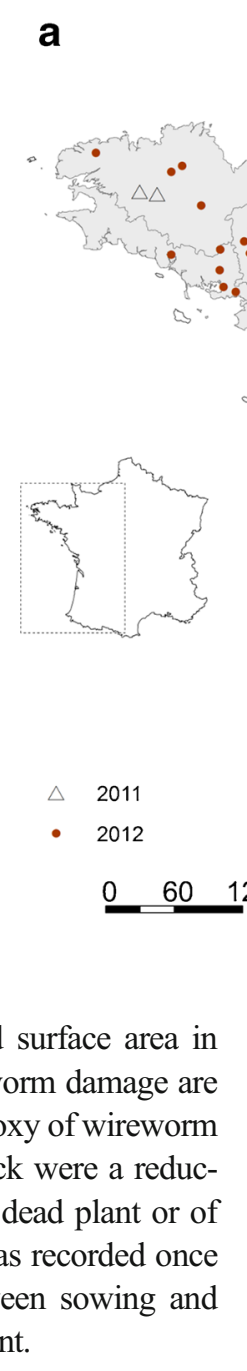

1977). Measuring the proportion of the field surface area in which well-identified symptoms due to wireworm damage are observed is considered by experts a reliable proxy of wireworm damage levels. Considered symptoms of attack were a reduction in seedling density, or the presence of a dead plant or of bleached stripes on leaves. This estimation was recorded once in the spring, and the number of days between sowing and damage assessment was also taken into account.

\subsection{Field selection}

One set of fields was formed in 2011 by recruiting volunteer farmers who contacted Arvalis Institut du Végétal complaining about former or current wireworm damage. To extend the range of infestation levels in the survey, one or two other maize fields belonging to the same farmers were randomly chosen and added to the 2012 set of fields, when possible. Therefore, the set of fields included in our survey cannot be considered a random sample of maize fields in the investigated area and probably exhibited higher levels of damage than the regional mean. However, this dataset was suitable for our purposes, i.e., to identify some agricultural and environmental factors that can influence local damage levels. This selection scheme, although relatively directed, allowed us to survey a wide range of damage levels (Fig. 2b).

\subsection{Data analysis}

A subset of 18 variables was identified as potential key factors driving the level of wireworm damage by Arvalis experts. Our study focused on the link between wireworm damage and the set of explanatory variables given in Table 1. All statistical analyses were carried out using R 3.0.1 software ( $R$ Development Core Team 2014).

\subsubsection{Selection of variables}

Variables exhibiting a high proportion of missing data or a low range of variation can mislead and/or impair the statistical analysis. To avoid these limitations, we set up a scheme for variable selection. We first applied a filter that consisted in retaining only the variables for which the proportion of missing values was lower than $40 \%$. For qualitative variables, we also checked whether the variable had at least two levels, each including at least five samples. If not, the variable was recoded by merging similar levels. A second filter was applied to prevent redundancy between variables. A similarity coefficient was calculated for each pair of variables as follows: When both variables were quantitative, their squared Pearson correlation was calculated; when both were qualitative, the square of their canonical correlation was used; and finally, when the pair of variables included a qualitative variable and a quantitative variable, a correlation ratio was calculated. We chose the arbitrary correlation threshold of 0.5 to discard a variable.

\subsubsection{Imputation of missing data}

Beta regression does not handle missing data; therefore, cases in which data were not available had to be treated beforehand. 
Two main approaches can be considered: either omitting individuals with one or more missing data values, or imputing a value to missing data. In our survey, about $47 \%$ of the samples (i.e., investigated fields) contained one or more missing data values; therefore, we decided to impute values to missing data. A robust, nonparametric method based on a random forest algorithm was applied using the missForest 1.4 package (Stekhoven and Bühlmann 2012). This method does not assume that data follow a normal distribution nor does it use prior information on the relationships between variables. Furthermore, it handles mixed datasets composed of quantitative and qualitative variables.

\subsubsection{Regression model}

The influence of the selected subset of variables on the wireworm damage, estimated through the proportion of damaged field area (DA) was assessed. To do so, we applied a beta regression model that is tailored to situations where the variable of interest is measured continuously on a restricted interval $(0,1)$. The beta regression model (Cribari-Neto and Zeileis 2010) assumes that the response variable is beta distributed by using a parameterization of the beta law indexed on the mean and a dispersion parameter. The explanatory variables can influence only one parameter or both. Here, we did not take interactions between variables into account and assumed that selected variables influenced only the mean of the response variable. Consequently, the dispersion parameter was held constant in the model. The link function used was a logit function. We extended the model to the extreme values 0 and 1 of the interval by using the transformation

$\mathrm{DA}=(\mathrm{DA} *(N-1)+0.5) / N)$,

where $D A$ is the response variable and $N$ is the number of statistical individuals. The beta regression was carried out using the betareg 3.0-4 package (Cribari-Neto and Zeileis 2010).

\subsubsection{Model selection and model average importance of variable}

We automatically generated all possible beta regression models, including all possible subsets of selected variables. To control for potentially influent variables that were not in the focus of our study, some variables were systematically included in the model: these forced variables were segment, year, and time between sowing and the observation date. The initial full model also included the type of insecticide, for which there were three levels due to suspected differences in efficiency (see Table 1).
Due to the number of possible models (approximately 2000), we performed an exhaustive search for the best model, i.e., the model with the smallest AIC. For each variable, its contribution to the explanatory power of the model was assessed by its average importance following the procedure of the glmulti 1.0.7 package (Calcagno and de Mazancourt 2010).

\section{Results and discussion}

\subsection{Variable selection}

Applying the entire selection process resulted in removing three variables out of the 18 variables due to a high proportion of missing values. Ultimately, we studied the effect of 11 putative explanatory variables and 4 forced variables on the wireworm damage. Table 1 shows the selected variables and the proportion of missing values before the imputation process. Correlation between variables never exceeded $35 \%$ except for the soil texture/segment pair, which showed a correlation of $41 \%$.

\subsection{Explanation of damages in 2011 and 2012}

Due to different schemes of field selection in 2011 and 2012 (see \$2.2), we analyzed the datasets separately for each year. In 2012, $12.6 \%$ of fields showed no damage and $40.5 \%$ were damaged across the entire field (Fig. 3d). This resulted in the best model being predominantly qualitative, i.e., mostly accounting for the presence or absence of wireworm damage and poorly for the intermediate levels of damage. To assess whether other variables could explain the intensity of damage, a complementary analysis was performed on 2012 data, excluding the fields with an extreme damage level (i.e., 0 or 1). The resulting subset included 104 fields.

In 2011, the best identified model accounted for $25 \%$ of the variance in field damage level. This can be attributed to the low variance in damage observed in 2011, with a low level of damage in most fields. In 2012, model accuracy was higher than in 2011 with $35 \%$ of the variance explained by the best model when all data were considered and $48 \%$ when extreme values were removed from the dataset. The entire range of infestation was represented better in 2012 in the observed dataset, although $53 \%$ of the fields exhibited no damage or complete $(100 \%)$ damage.

The accuracy of the best models was moderate (Fig. 3b, $\mathrm{d}, \mathrm{f}$ ). Such moderate accuracy was also observed in the study of the influence of agricultural or landscape variables on the wireworm population (Parker and Seeney 1997). The absence of a strong fit suggests that some important effects had been missed. Alternatively, it could result from a strong inertia in 
the location of wireworm populations that leads to their presence being strongly dependent on their past presence in the field and not only on recent or current agroenvironmental field's characteristics.

As expected, treated fields (whatever the type of insecticide) showed less damage than untreated ones (Table 2). However, in 2012, when extreme values of damage were removed from the analysis, the intensity of damage was surprisingly higher in treated fields. This may result from a tendency for farmers to apply insecticide in heavily damaged fields and from a partial inefficacy of the treatment. Results showed, as expected, that the longer the duration between sowing and observation, the higher the observed level of damage was in both years. However, the opposite effect was observed in 2012 when only intermediate levels of damage were considered. This effect may result from attacks having occurred later in the season and thereby being less intense.

Agricultural variables were always identified as the most important variables to explain wireworm damage in 2011 and 2012 (Fig. 3a, c, e): Consequently, these variables were always included in the final best models. Environmental variables were important only in 2012, especially for explaining intermediate damage levels (Fig. 3e).

\subsection{Effect of agricultural practices}

The practices applied during the cropping season, especially the tillage practices, were among the most important factors in determining wireworm damage (Fig. 3a, c, e). The tillage effect on macrofauna is complex and may vary among species depending on their ecology and biology. It had been evidenced in several previous studies. For example, there were more Elateridae beetles in Costa Rican pineapple crops when a minimal tillage strategy was applied (Rojas Acuña and Camacho Buberth 2004). Therefore, we assumed that tillage had a negative influence on the damage caused by wireworms. Likewise, Furlan (2005) recommended tilling when wireworms are the most vulnerable. Because larvae migrate up to the upper soil layers in spring and move down into deeper layers in winter (e.g., Miles and Petherbridge 1927), we postulated that the tillage effect would appear only in the spring and not in the winter.

In our study, the number of tillage operations was included in the best models in 2011 and 2012 (Table 2). The quantification of the relative importance of tillage compared to other agroenvironmental factors is relatively new. Here, we consistently found tillage as the main determinant factor of damage. However, although the number of spring tillage operations was always found in the best model with an importance ranging from 0.8 to 1 (Fig. 3a, c, e), the direction of its effect was not consistent over the 2 years (Table 2). This discrepancy suggests an interaction between spring tillage and other factors that fluctuate from year to year, such as climate. In 2012, the number of tillage operations was negatively associated with the level of damage (Table 2), which is consistent with other published studies. This negative effect appeared in the spring, but surprisingly also in the winter of 2012, in both datasets with or without considering the extreme damage levels. Therefore, tillage may influence the presence/absence of wireworms as well as the intensity of the damage they inflict. Despite the fact that winter tillage has weaker effect than spring tillage, our results underlined the importance of winter tillage on reducing damage. Its importance ranged from 0.3 to 0.7 (Fig. 3a, c, e). The influence of winter tillage in 2012 may also result from the particular climatic conditions in autumn 2011 and the beginning of winter 2011-2012, which were particularly mild (source Météo France-Arvalis Institut du Vegetal). During a mild and humid winter, larvae can remain active at the soil surface and therefore be damaged by tillage.

Secondly, our results highlighted the presence of a grass phase in recent crop rotations as the second most important agricultural variable. Its importance was 0.85 in 2011 and 1 in 2012, when extreme damage levels, i.e., 0 and 1, were taken into account (Fig. 3a, c). It was positively correlated with damage in both years (Table 2). This is consistent with the literature, which reports that grassland is the natural habitat of wireworms (Parker and Howard 2001) and the preferred laying site for females (e.g., Benefer et al. 2010). However, when extreme values of damage were removed from the analysis of 2012 data, its importance decreased to 0.3 (Fig. 3e). This suggests that the presence of a grass ley in the crop rotation sequence increases the probability of damage, but only to a lesser degree of its intensity.

The importance of the rotation sequence varied from 0.1 to 0.3 (Fig. 3a, c, e). This suggests that, except for the presence of a grass ley whose effect is captured by the "grass ley history" variable, the rotation sequence had no major effect on wireworm damage. This result is surprising since previous studies had identified the rotation sequence as a key factor in determining wireworm damage and populations (Miles and Petherbridge 1927; Furlan 2005). However, our characterization of the rotation sequence differs from previous studies. Here, the factor "rotation sequence" had four levels: maize monoculture, a short rotation sequence with a maximum of two crops, a long rotation sequence with more than three crops, and a rotation sequence that included a grass ley in the last 5 years. Taken altogether, these results indicate that the longterm effect of the presence of a grass ley in the fields' past was only slightly influenced by the present rotation sequence. This effect can be attributed to the capacity of wireworms to endure long periods of starvation (Furlan 2004) and to feed on a large variety of plants (Traugott et al. 2008) or to adapt their diet to available plant diversity (Schallhart et al. 2012). Thus, our findings suggest a strong inertia in the distribution of wireworm populations. 
Fig. 3 Regression models of wireworm damage in maize in western France in 2011 and 2012. Average importance of explanatory variables for 2011 data (a), for 2012 data including extreme values (c), and for 2012 data excluding extreme values of the response variable (i.e., field damage level) (e). The explanatory variables included in the best model are shown in green. Best model predictions of field damage level plotted against observed field damage level: b linear regression equation $Y=$ $0.21+0.22 * X$ and $R^{2}=0.25$ for 2011 data; $\mathbf{d}$ linear regression equation $Y=0.43+0.28 * X$ and $R^{2}=0.35$ for 2012 data including extreme values; $\mathbf{f}$ linear regression equation $Y=0.28+0.44 * X$ and $R^{2}=0.48$ for 2012 data excluding extreme values. Light gray circles summarize data points: They are centered on the median of predictions for each observed damage level, with a radius proportional to the number of fields that showed the same level of damage (color figure online)

\section{Variables}

a

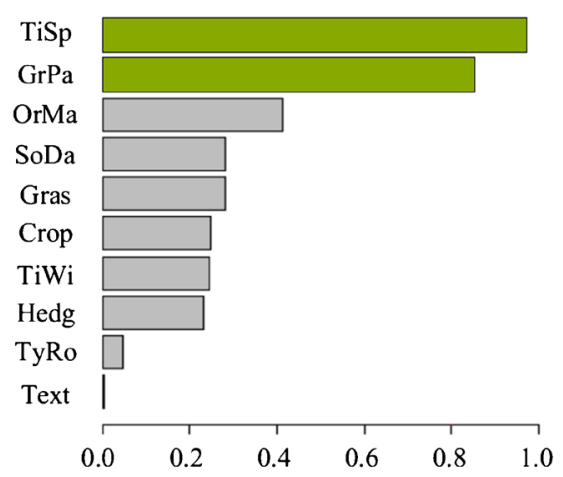

C

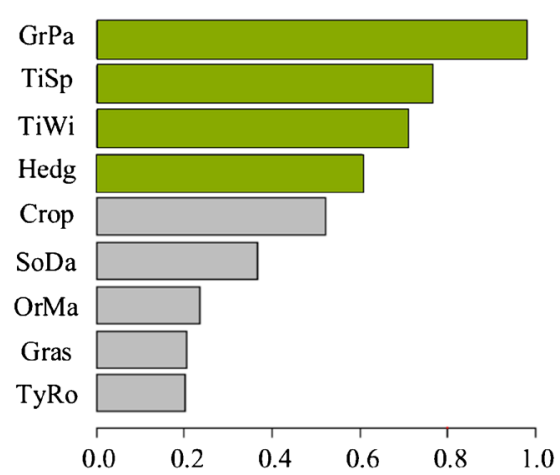

e

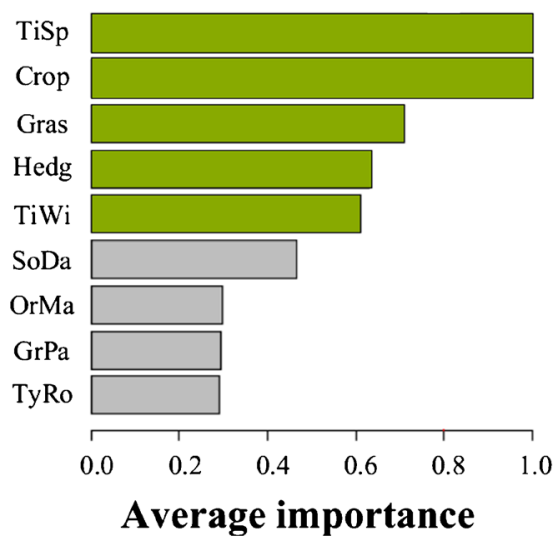

\section{Predicted values}

b

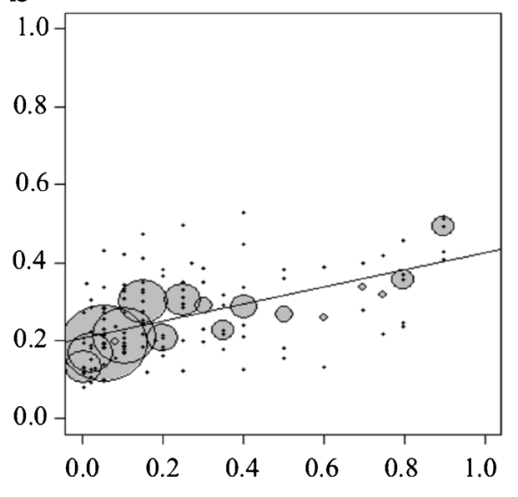

d

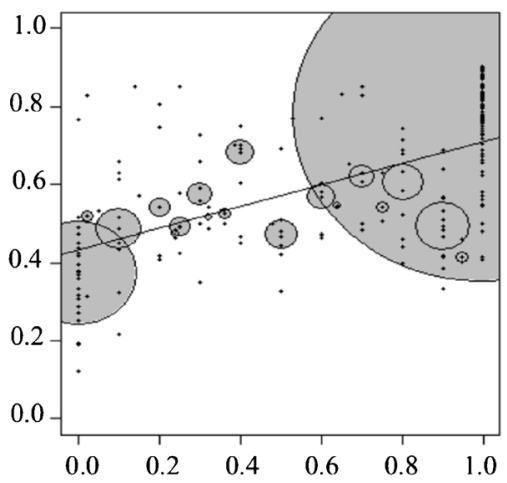

f

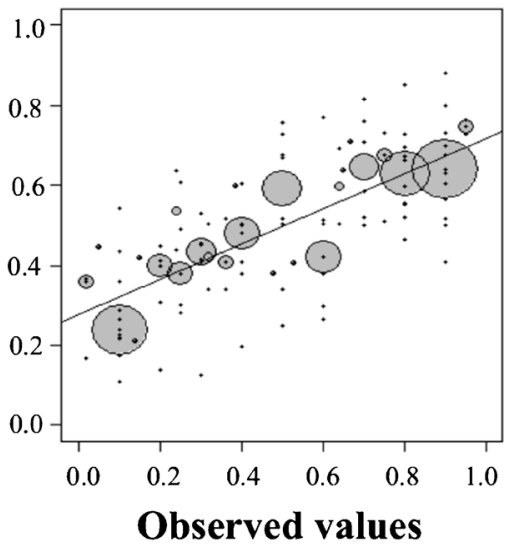

Sowing date was never identified as an important variable to explain damage in our study contrary to the conclusions reached thus far at the Arvalis Institut du Végétal (unpublished data). Its importance ranged from 0.3 to 0.5 (Fig. 3a, c, e).

\subsection{Effect of the local landscape features}

The environment also exhibited a significant effect on wireworm damage (Fig. 3c, e). In the literature, several studies have shown a link between landscape context and (i) wireworms and (ii) male click beetle population, or between landscape context and damage (Benefer et al. 2012; Blackshaw and Hicks 2013; Hermann et al. 2013). We therefore expected that local landscape features would influence damage in maize. In our study, local landscape features did indeed influence moderate damage, but only in 2012 and especially when extreme damage levels were removed from the dataset.

Hedges are usually shown to increase local biodiversity by acting as a habitat or a corridor for adults of many insect species 
(Duelli et al. 1990). Hedges are positively correlated with damage. Here, we found a significant importance (equal to 0.6) of the presence of hedges in 2012 (Fig. 3c, e). However, its effect differed according to whether the extreme values of damage were considered or not (Table 2). It increased the damage probability but decreased its intensity (Table 2). We assume that the absence of hedges contributes to field instability, which results in sporadic, but strong outbreaks. In contrast, the stabilizing effect of a hedge at the perimeter of a field results in the continuous hosting of wireworm populations, but these

Table 2 Coefficients of the explanatory variables in the best model describing wireworm damage in 2011 and in 2012, with and without extreme damage values

\begin{tabular}{|c|c|c|c|}
\hline \multirow[t]{2}{*}{ Variables } & \multirow[t]{2}{*}{ Coefficient estimates (2011) } & \multicolumn{2}{|l|}{ Coefficient estimates (2012) } \\
\hline & & With extreme damage values & Without extreme damage values \\
\hline Intercept & -1.99 & -0.26 & 2.41 \\
\hline \multicolumn{4}{|l|}{ Agricultural practices } \\
\hline $\mathrm{TiSp}$ & 0.33 & -0.21 & -0.40 \\
\hline TiWi & $N B M$ & -0.38 & -0.41 \\
\hline $\mathrm{GrPa}$ & & & $N B M$ \\
\hline Absent & 0 & 0 & \\
\hline Present & 0.53 & 0.51 & \\
\hline \multicolumn{4}{|l|}{ Landscape context } \\
\hline Hedg & $N B M$ & & \\
\hline Absent & & 0 & 0 \\
\hline Present & & 0.41 & -0.56 \\
\hline Crop & $N B M$ & $N B M$ & \\
\hline Absent & & & 0 \\
\hline Present & & & -0.81 \\
\hline Gras & $N B M$ & $N B M$ & \\
\hline Absent & & & 0 \\
\hline Present & & & 0.46 \\
\hline \multicolumn{4}{|l|}{ Forced variables } \\
\hline \multicolumn{4}{|l|}{ TyIn } \\
\hline None & 0 & 0 & 0 \\
\hline Pyrethroid (microgranular) & -0.43 & -0.37 & 0.67 \\
\hline Thiamethoxam (seed treatment) & -0.68 & -0.33 & 0.53 \\
\hline DuSO & 0.01 & 0.01 & -0.02 \\
\hline \multicolumn{4}{|l|}{ Segm } \\
\hline 1 & 0 & 0 & 0 \\
\hline 2 & NA & 0.9 & 0.14 \\
\hline 3 & NA & 1.13 & NA \\
\hline 4 & -0.08 & -0.92 & -1.11 \\
\hline 5 & 0.16 & -0.38 & 0.52 \\
\hline 6 & -0.26 & -0.38 & 0.27 \\
\hline 7 & -0.65 & -0.22 & -0.17 \\
\hline 8 & 0.01 & 0.64 & -0.21 \\
\hline 9 & 0.12 & -1.22 & 0.04 \\
\hline 10 & 0.14 & 0.76 & -0.46 \\
\hline 11 & -0.01 & 1.45 & 0.03 \\
\hline 12 & -0.08 & 2.36 & 0.19 \\
\hline 13 & -0.78 & 2.22 & -0.8 \\
\hline 14 & -0.8 & 2.67 & NA \\
\hline
\end{tabular}

For qualitative variables, the first level was used as a reference to estimate the coefficient of the other levels

$N B M$ not included in the best model, $N A$ not present in the sample, see Table 1 for full variable names 
populations may be more efficiently controlled by their natural antagonists. This hypothesis needs to be tested in the future with specifically designed studies.

The two other landscape variables (adjacent grasslands and other crops) had an effect only on the level of damage in 2012 (Fig. 3e). The grassland is classically considered as a favorable habitat for wireworms (Blackshaw and Vernon 2006; Blackshaw and Hicks 2013). Our results indicated that its presence at the field perimeter increased damage compared to cultivated crops (coefficient estimates were 0.46 and -0.81 respectively). We therefore suggest that neighboring grassland provides a source of adult click beetles that might oviposit in the field and lead to subsequent damage. On the contrary, the presence of other crops may produce a dilution effect in the population of adult click beetles in the landscape. This would lead to a decrease in the oviposition rate and consequently in damage, in the surveyed field.

\subsection{Effect of soil properties}

Interestingly, soil properties were never found to be important in explaining wireworm damage. The importance of soil texture ranged from 0 to 0.4 (Fig. 3a, c, e). To our knowledge, no previous studies have shown any influence of soil texture only on wireworm damage. Jung et al. (2012) studied the soil type in interaction with soil moisture and showed that the moisture preference of wireworms depended on the type of soil in which they are found. Using this interaction, a model was built on the presence or absence of larvae in upper soil profile with a prediction accuracy of about $80 \%$. This underlines the importance of interactions between microclimate and soil structure.

Several studies have addressed the influence of soil organic matter content on wireworm populations. Salt and Hollick (1946) reported a correlation between wireworm distribution and soil organic matter content due to the putative capacity of larvae to feed on organic matter. However, Traugott et al. (2008), using an isotope analysis, showed that wireworms consume a negligible amount of organic matter. Nevertheless, organic matter content may influence soil favorability to wireworms through its effect on soil structure, which can impede or facilitate movement and detection of food via volatile compounds released in the rhizosphere (Gfeller et al. 2013). In our study, a slight or null effect of organic matter content was detected. Its importance ranged from 0.2 to 0.4 .

Our failure to identify an effect of soil properties may be due to the absence of distinction between the wireworm species present in the surveyed fields. Click beetle species differ in their preferences of soil properties and climate characteristics (Staudacher et al. 2013). Similarly, the effect of organic matter content depends on the considered species and cannot be detected without prior species identification (Benefer et al. 2012). Therefore, species must be identified to address the impact of soil properties on damage. Indeed, recent work (Furlan 2014) emphasizes the relationship between wireworm species and crop damage.

\section{Conclusion}

Our study was based on a vast agroenvironmental survey: More than 340 fields were surveyed over two consecutive years. It was underpinned by a combination of statistical methods to address the influence of several variables with potentially high correlations and high rates of missing values on the proportion of damaged crop area. Our approach implements a useful framework for other investigations involving similar datasets.

Overall, this study was the first step toward the design of new, ecologically inspired strategies to protect maize crops from wireworms. Our results confirmed that agricultural practices are among key determinants in crop damage caused by wireworms in western France. In addition, we provided a ranking of the effects. Tillage appeared to be the most important factor because its effect was identified in all models. However, it varied according to year and season of application. The presence of a grass ley was the second most influential factor. We showed that it mostly increased the occurrence of damage rather than its intensity. A moderate effect of the local landscape features was demonstrated, though not stable over the two consecutive years of study. Surprisingly, soil properties did not emerge as key factors in explaining wireworm damage. However, it may result from a lack of accuracy in the assessment of these factors.

Our results showed some inconsistencies in the effect of some variables (e.g., spring and winter tillage and hedge presence) over the 2 years, which we attribute to potentially complex interactions. We also believe that it would be appropriate to consider the wireworm species as an additional explanatory variable in future studies (Furlan 2014). Species traits and life cycles differ dramatically (Blackshaw and Vernon 2006; Staudacher et al. 2013). This study underlines the complexity of interactions between agroenvironmental factors with respect to their effect on wireworms and advocates further study on wireworm biology. Among others, we believe that habitat requirement for larvae and its variability among species, oviposition behavior, and preferences of adults, as well as the identification of the main antagonists and their impact on wireworm populations would deserve specific consideration.

Acknowledgments The study was conducted as a part of the project "Crop protection against wireworm attacks: forecast of risks and new control strategy" with financial support from the French Ministry for Agriculture (CASDAR, project no. 1133). We thank the maize farmers who accepted to participate in the survey and all the people who collected field data, especially the regional Arvalis staff members: E. Masson, M. Moquet, S. Renac, A-M Bodilis, G. Clouté, and G. Espagnol. SP acknowledges the INRA metaprogram "Sustainable Management of Crop Health" for funding the COPACABANA project. The authors thank two anonymous referees for their careful reading and helpful suggestions. 


\section{References}

Barsics F, Haubruge E, Verheggen F (2013) Wireworms' management: an overview of the existing methods, with particular regards to agriotes spp. (Coleoptera: Elateridae). Insects 4(1):117-152. doi: 10.3390/insects4010117

Benefer CM, Andrew P, Blackshaw R, Ellis J, Knight M (2010) The spatial distribution of phytophagous insect larvae in grassland soils. Appl Soil Ecol 45(3):269-274. doi:10.1016/j.apsoil.2010.05.002

Benefer CM, Knight ME, Ellis JS, Hicks H, Blackshaw RP (2012) Understanding the relationship between adult and larval Agriotes distributions: the effect of sampling method, species identification and abiotic variables. Appl Soil Ecol 53:39-48. doi:10.1016/j. apsoil.2011.11.004

Blackshaw RP, Hicks H (2013) Distribution of adult stages of soil insect pests across an agricultural landscape. J Pest Sci 86(1):53-62. doi: $10.1007 / \mathrm{s} 10340-012-0413-6$

Blackshaw RP, Vernon RS (2006) Spatiotemporal stability of two beetle populations in non-farmed habitats in an agricultural landscape. J Appl Ecol 43(4):680-689. doi:10.1111/j.1365-2664.2006.01167.x

Calcagno V, de Mazancourt C (2010) Glmulti: an r package for easy automated model selection with (Generalized) linear models. J Stat Softw 34(12): 1-29

Chaton P-F, Mauras R, Ravanel P, Meyran J-C, Tissut M (2003) Taupins, comment les larves attaquent: les stratégies phytophages des larves d'Agriotes (Coléoptères, Elatéridés) sur la plantule de maïs. Phytoma 557:41-45

Cherry R, Stansly P (2008) Abundance and spatial distribution of wireworms (Coleoptera: Elateridae) in Florida sugarcane fields on muck versus sandy soils. Florida Entomol 91(3):383-387

Cribari-Neto F, Zeileis A (2010) Beta regression in R. J Stat Softw 34(2): $1-24$

Development Core Team R (2014) R: a language and environment for statistical computing. R Foundation for Statistical Computing, Vienna

Doane JF (1977) Spatial pattern and density of Ctenicera destructor and Hypolithus bicolor (Coleoptera: Elateridae) in soil in spring wheat. Can Entomol 109(06):807-822. doi:10.4039/Ent109807-6

Duelli P, Studer M, Marchand I, Jakob S (1990) Population movements of arthropods between natural and cultivated areas. Biol Conserv 54(3):193-207. doi:10.1016/0006-3207(90)90051-P

Erichsen JJR (1944) The elaterid population of Mid- and West Wales. Issue Proc Zool Soc Lond 114(3):350-359. doi:10.1111/j.10963642.1944.tb00230.x

Furlan L (2004) The biology of Agriotes sordidus Illiger (Col., Elateridae). J Appl Entomol 128(9-10):696-706. doi:10.1111/j. 1439-0418.2004.00914.696-706

Furlan L (2005) An IPM approach targeted against wireworms: what has been done and what has to be done. IOBC/wprs Bull 28(2):91-100

Furlan L (2014) IPM thresholds for Agriotes wireworm species in maize in Southern Europe. J Pest Sci 1-9. doi:10.1007/s10340014-0583-5

Geiger F, Bengtsson J, Berendse F, Weisser WW, Emmerson M, Morales MB, Ceryngier P, Liira J, Tscharntke T, Winqvist C, Eggers S, Bommarco R, Pärt T, Bretagnolle V, Plantegenest M, Clement LW, Dennis C, Palmer C, Oñate JJ, Guerrero I, Hawro V, Aavik T, Thies C, Flohre A, Hänke S, Fischer C, Goedhart PW, Inchausti P (2010) Persistent negative effects of pesticides on biodiversity and biological control potential on European farmland. Basic Appl Ecol 11(2): 97-105. doi:10.1016/j.baae.2009.12.001
Gfeller A, Laloux M, Barsics F, Kati DE, Haubruge E, du Jardin P, Verheggen FJ, Lognay G, Wathelet JP, Fauconnier ML (2013) Characterization of volatile organic compounds emitted by barley (Hordeum vulgare L.) roots and their attractiveness to wireworms. J Chem Ecol 39(8):1129-1139. doi:10.1007/s10886-013-0302-3

Gough HC, Evans AC (1942) Some notes on the biology of the clickbeetles Agriotes obscurus L. and A. sputator L. Ann Appl Biol 29(3):275-279. doi:10.1111/j.1744-7348.1942.tb07594.x

Hermann A, Brunner N, Hann P, Wrbka T, Kromp B (2013) Correlations between wireworm damages in potato fields and landscape structure at different scales. J Pest Sci 86(1):41-51. doi:10.1007/s10340-0120444-z

Jung J, Racca P, Schmitt J, Kleinhenz B (2012) SIMAGRIO-W: development of a prediction model for wireworms in relation to soil moisture, temperature and type. J Appl Ecol. doi:10.1111/jen.12021

Lees AD (1943) On the behaviour of wireworms of the genus Agriotes Esch. (Coleoptera, Elateridae) I. Reaction to humidity. J Exp Biol 20:43-53

Miles HW (1942) Wireworms and agriculture, with special reference to Agriotes Obscurus L. Ann Appl Biol 29(2):176-180. doi:10.1111/j. 1744-7348.1942.tb07585.x

Miles HW, Petherbridge FR (1927) Investigation on the control of wireworms. Ann Appl Biol 14(3):359-387. doi:10.1111/j.1744-7348. 1927.tb07017.x

Oerke EC, Dehne HW (2004) Safeguarding production-losses in major crops and the role of crop protection. Crop Prot 23(4):275-285. doi: 10.1016/j.cropro.2003.10.001

Parker WE, Howard JJ (2001) The biology and management of wireworms (Agriotes spp.) on potato with particular reference to the U.K. Agric For Entomol 3(2):85-98. doi:10.1046/j.1461-9563. 2001.00094.x

Parker WE, Seeney FM (1997) An investigation into the use of multiple site characteristics to predict the presence and infestation level of wireworms (Agriotes sup., Coleoptera: Elateridae) in individual grass fields. Ann Appl Biol 130(3):409-425. doi:10.1111/j.17447348.1997.tb07671.x

Rojas Acuña LA, Camacho Buberth G (2004) Piña (Ananas comosus L. Merr) sembrada en labranza mínima y labranza convencional en San Carlos. Costa Rica Agron Mesoamericana 15(2):161-172

Salt G, Hollick FSJ (1946) Studies of wireworm populations. II. Spatial distribution. J Exp Biol 23(1):1-46

Schallhart N, Tusch MJ, Wallinger C, Staudacher K, Traugott M (2012) Effects of plant identity and diversity on the dietary choice of a soilliving insect herbivore. Ecology 93(12):2650-2657. doi:10.1890/ 11-2067.1

Staudacher K, Schallhart N, Pitterl P, Wallinger C, Brunner N, Landl M, Kromp B, Glauninger J, Traugott M (2013) Occurrence of Agriotes wireworms in Austrian agricultural land. J Pest Sci 86(1):33-39. doi:10.1007/s10340-011-0393-y

Stekhoven DJ, Bühlmann P (2012) MissForest—non-parametric missing value imputation for mixed-type data. Bioinformatics 28(1):112118. doi:10.1093/bioinformatics/btr597

Taupin P (2007) Dossier taupin. Culture par culture. Une lutte de longue haleine. Perspect Agric 339:27-31

Traugott M, Schallhart N, Kaufmann R, Juen A (2008) The feeding ecology of elaterid larvae in central European arable land: new perspectives based on naturally occurring stable isotopes. Soil Biol Biochem 40(2):342-349. doi:10.1016/j.soilbio.2007.08.013

Wilson C, Tisdell C (2001) Why farmers continue to use pesticides despite environmental, health and sustainability costs. Ecol Econ 39(3):449-462. doi:10.1016/s0921-8009(01)00238-5 